\title{
Side Effects of Pfizer-BioNTech COVID-19 Vaccine among Libyan Young Adults: Observational Study
}

\author{
Taher I. Shailabi ${ }^{*}$, Elham O. Borwis ${ }^{2}$, Nisreen Saed Majeed1, Nagat H. Bubtina ${ }^{3}$, \\ Naeima Betamar', Guma Abdeldaim ${ }^{2}$ \\ ${ }^{1}$ Pharmacology and Toxicology Department, Faculty of Pharmacy, Omar Al-Mukhtar University, Al-Bayda, Libya \\ ${ }^{2}$ Medical Microbiology Department, Faculty of Medicine, Benghazi University, Benghazi, Libya \\ ${ }^{3}$ Conservative Dentistry Department, Faculty of Dentistry, Benghazi University, Benghazi, Libya \\ Email: *taher.issa@omu.edu.ly
}

How to cite this paper: Shailabi, T.I., Borwis, E.O., Majeed, N.S., Bubtina, N.H., Betamar, N. and Abdeldaim, G. (2022) Side Effects of Pfizer-BioNTech COVID-19 Vaccine among Libyan Young Adults: Observational Study. Journal of Biosciences and Medicines, 10, 33-45.

https://doi.org/10.4236/ibm.2022.101005

Received: December 5, 2021

Accepted: January 10, 2022

Published: January 13, 2022

Copyright $\odot 2022$ by author(s) and Scientific Research Publishing Inc. This work is licensed under the Creative Commons Attribution International License (CC BY 4.0).

http://creativecommons.org/licenses/by/4.0/

\begin{abstract}
Purpose: Since the mRNA technology used to manufacture Pfizer-BioNTech COVID-19 Vaccine is new, it is still difficult to predict its consequences. However, many young people, especially in developing countries, think that they are less susceptible to severe infection with the Coronavirus 2 (SARSCoV-2), Therefore, they do not prefer to take the COVID-19 vaccines. Accordingly, studies in this aspect are necessary to increase people's awareness of the acceptance of vaccination, especially for the youth. Patients and Methods: This study was conducted on healthy young adults of both sexes. Participants $(\mathrm{n}=81)$ were received two doses of the Pfizer-BioNTech COVID-19 Vaccine. A paper questionnaire was prepared, the survey asks about the side effects related to receiving the Vaccine. All participants completed the questionnaire twice, once after the first dose and again after the second dose. Data were collected and statistically analyzed. Results: The most common side effects were Muscle pain, Tiredness, Headache, and Fever. Less common side effects were Chills, Fainted, Breathlessness, and Coughing. Rare side effects include nausea and vomiting, Diarrhea, Anaphylactic Reaction, and Swollen Lymph Nodes. Side effects that are strongly associated with females are Headache, and Joint pain, for males, Anaphylactic reaction. The study revealed a significant difference between the number of females (96.5\%) and males (85\%) who suffered from the side effects of the Pfizer-BioNTech COVID-19 Vaccine $(P=0.033)$. Conclusion: Most of the side effects reported in our study were consistent with Pfizer's fact sheet for recipients and caregivers. Through our follow-up to the participants in the study, we noticed that the reported side effects were not too bad, and they were able to carry out their daily activities, so we recommend taking the vaccine, especially for young people.
\end{abstract}




\section{Keywords}

Pfizer-BioNTech, Side Effects, COVID-19 Vaccine, Young Adults

\section{Introduction}

Coronavirus 2 (SARS-CoV-2) broke out at the end of 2019, and soon after, the virus spread, causing a high mortality and morbidity rate worldwide [1]. In March 2020 World Health Organization has been declared SARS infection a global pandemic [2]. The elder people, and those suffering from certain diseases, are at the highest risk for COVID-19 infection and its complications, more recent data showed that the COVID-19 infection may affect younger people [3]. Although Governments and institutions around the world have taken several safety measures to limit the pandemic's spread, developing a vaccine is the only hope to stop the threat [4].

Several types of COVID-19 vaccines have been developed to combat this pandemic, including Pfizer-BioNTech, Moderna, Sinopharm, Sinovac, Sputnik V, Janssen (Johnson \& Johnson's) and AstraZeneca. These vaccines have been verified to be effective to prevent the infection of COVID-19 at varying efficacy, each kind of vaccine has a subtle structure, pros and cons with respect to efficacy, immunogenicity and safety [5] [6].

COVID-19 vaccine-specific mild adverse reactions have been recorded after receiving first, second or both doses include: fever, headache, myalgia, pain at injection site, arthralgia, fatigue, chills and lymphadenopathy, etc with variation either mild or sever among given vaccines [7]. Some factors have been shown to be correlated with the frequency of side effects and severity, include gender differences; where it was found that female has been consistently associated with an increased risk of side effects than male after different types of COVID-19 vaccines as well as the severity of side effects after the second dose were usually higher than the first dose [1] [8] [9]. Several studies have been performed to record short term side effects of COVID-19 vaccines in order to investigate the long-term safety and efficacy [10].

The Pfizer-BioNTech COVID-19 Vaccine was approved by the US Food and Drug Administration (FDA) on December 11, 2020, for emergency use in individuals 16 years of age and older [11]. The vaccination requires two doses, at least 21 days apart. Its effectiveness has been reported to be around 95\%. After vaccination, some side effects may occur, as a response to building immunity. These symptoms may include Muscle pain, Tiredness, Headache, Fever, Swelling, Joint pain, Tingling, Itching, Chills, and Fainted [12].

Since the mRNA technology used to make Pfizer-BioNTech COVID-19 Vaccine is new, it is still difficult to predict its consequences. Additionally, rumors around the useless of vaccine effectiveness and the adverse reactions among young people, especially in developing countries, obstacle the efforts COVID-19 
vaccine campaign to reach the community. Accordingly, studies in this aspect are necessary to increase people's awareness of the acceptance of vaccination, especially for the youth. The current study aims to follow up and short-term side effects after receiving the Pfizer-BioNTech COVID-19 Vaccine in a sample of young people. Also studying the correlations between side effects and which groups are most susceptible to side effects within the study sample.

\section{Materials and Methods}

This study was conducted after approval from Scientific Research Ethics Committee (SREC), Faculty of Dentistry, Benghazi University, Libya (No. 074) Written approval (Informed consent) was obtained from all study participants. The study was conducted at the Faculty of Pharmacy, Omar Al-Mukhtar University, Al-Bayda, Libya.

\subsection{Participants}

Participants accepted in this study fulfilled the following criteria "youth people, both genders, healthy/or participants with the clinically controlled disease, did not have any respiratory disease, pregnant and breastfeeding women are not allowed, participants will only be included after signing the voluntary (Informed Consent Form)". The sample consisted of 81 participants, including 69 women and 12 men with ages ranging from 19 to 25 years, who attended the Faculty of Pharmacy, Omar Al-Mukhtar University, Al-Bayda, Libya, between July 2021, and September 2021.

All participants were subjected to the following:

A detailed assessment of history, with a special focus on age, sex, height, body Weight, Diabetes mellitus, Systolic blood pressure Diastolic blood pressure.

All participants received two doses of the Pfizer-BioNTech COVID-19 Vaccine (BNT162b2), manufactured by: Pfizer, Inc., and BioNTech.

Undergo prepared survey twice at baseline (1 - 14 days after the first dose), and final ( 1 - 14 days after the second dose).

A paper questionnaire was prepared, written in Arabic, and scientific terms were clarified in the public language. The questionnaire was delivered to each participant, and a filling method was clarified. Participants were also provided with the phone numbers of the researchers conducting the study, to answer any questions regarding the questionnaire. Participants were volunteers and were not given any incentive.

The survey asks about the side effects related to receiving the Pfizer-BioNTech COVID-19 Vaccine. Participants were also asked to mention any other symptoms not mentioned in the questionnaire.

The questionnaire includes questions about if any of the following symptoms occur: (Muscle pain, Tiredness, Headache, Fever, Swelling, joint pain, Tingling, Itching, Chills, Fainted, Breathlessness, Coughing, Redness, Nausea and vomiting, Diarrhea, Anaphylactic Reaction, Swollen Lymph Nodes, and Onset of 
Symptoms).

\subsection{Statistical Analysis}

The "Mann Whitney test" was used to analyze differences between any two groups in the study. The correlation analysis between change in one side effect caused by Pfizer-BioNTech COVID-19 Vaccine and other parameters (Table 3) was also carried out by Spearman's correlation coefficient (r). At a $95 \%$ confidence interval, a p-value of $<0.05$ was regarded to indicate statistical significance. All results are reported as a percent or mean, and \pm standard deviation. P-values $(<0.05)$ were considered statistically significant. All statistical analyses were conducted using GraphPad Prism version 8.0.1 for Windows, GraphPad Software, San Diego, California USA, https://www.graphpad.com/.

\subsection{Ethics Statement}

All procedures of this study were approved and regularly controlled by the SREC, Faculty of Dentistry, Benghazi University, Libya (No. 074), and all experiments were performed by the guidelines and regulations of this committee. All the procedures were also carried out in full accordance with the Council for International Organizations of Medical Sciences (CIOMS) ethical guidelines 2017 [13].

\section{Results}

\section{Participants characteristics, number of doses, and reported side effects}

A number of 81 people participated in this study, all of them were students of the Faculty of Pharmacy, Omar Al-Mukhtar University, Al-Bayda, Libya, males were the minority of participants $(12,14.8 \%)$, which actually represent the percentage of male students studying at the Faculty of Pharmacy in the different academic years ranges from $10 \%$ to $14 \%$, compared to the percentage of female students. It was found that the participants average age was $(21.5, \pm 1.7$ years), with mean body mass index $\left(23.1, \pm 3.5 \mathrm{~kg} / \mathrm{m}^{2}\right)$, mean systolic blood pressure was (118.5, $\pm 6.3 \mathrm{mmHg})$, and mean diastolic blood pressure was $(78.2, \pm 5.3 \mathrm{mmHg})$. Two of the participants were diabetics (2.5\%). All study participants $(81,100 \%)$ had received their first Pfizer-BioNTech COVID-19 Vaccine dose, while (54, $66.6 \%)$ had received both doses. After they received their first dose, $(75,92.6 \%)$ of the participants reported the appearance of side effects, and after they received their second dose, $(53,98.1 \%)$ of the participants reported the appearance of side effects. After both doses, the incidence of side effects was higher in females than in males, which were (96.5\%), and (85.0\%) respectively. Please take note of the following items when proofreading spelling and grammar:

Reported Pfizer-BioNTech COVID-19 Vaccine Side Effects and their Correlation with the first and second doses

The results showed an increase in the number of participants who were suffering from side effects after receiving the second dose of the Pfizer-BioNTech 
COVID-19 Vaccine (53, 98.1\%), compared to those who reported side effects after receiving the first dose $(75,92.6 \%)$. No significant differences were observed when comparing each side effect individually after the first and second dose, except for Chills $(\mathrm{P}=0.001)$ and Breathlessness $(\mathrm{P}=0.034)$ (Table 1$)$. The most common reported side effects after both doses were Muscle pain $(66.7 \%), \mathrm{Ti}$ redness (60.7\%), Headache (57.0\%), and Fever (49.6\%) (Figure 1).

Table 1. Participant's characteristics, and Pfizer-BioNTech COVID-19 Vaccine parameters of participants at baseline and final of study.

\begin{tabular}{|c|c|c|c|c|}
\hline & \multicolumn{4}{|c|}{ Participants } \\
\hline & $\begin{array}{l}\text { Baseline } \\
(\mathrm{N}=81)\end{array}$ & $\begin{array}{c}\text { Final } \\
(\mathrm{N}=54)\end{array}$ & $\mathrm{P}$-value & $\begin{array}{l}\text { P-value } \\
\text { summary }\end{array}$ \\
\hline Age (years), mean $\pm S D$ & $21.5( \pm 1.7)$ & $21.6( \pm 1.8)$ & 0.854 & Ns \\
\hline Men, n (\%) & $12(14.8)$ & $8(14.8)$ & $>0.999$ & Ns \\
\hline $\mathrm{BMI}\left(\mathrm{kg} / \mathrm{m}^{2}\right)$, mean $\pm \mathrm{SD}$ & $23.1( \pm 3.5)$ & $23.2( \pm 3.8)$ & 0.876 & Ns \\
\hline Diabetes mellitus, n (\%) & $2(2.5)$ & $1(1.9)$ & 0.819 & Ns \\
\hline $\begin{array}{l}\text { Systolic BP }(\mathrm{mmHg}) \\
\text { mean }( \pm \mathrm{SD})\end{array}$ & $118.5( \pm 6.3)$ & $117.8( \pm 7.6)$ & 0.544 & Ns \\
\hline $\begin{array}{c}\text { Diastolic BP }(\mathrm{mmHg}) \\
\text { mean }( \pm \mathrm{SD})\end{array}$ & $78.2( \pm 5.3)$ & $77.5( \pm 5.8)$ & 0.558 & Ns \\
\hline Muscle pain, $n,(\%)$ & $57(70.4)$ & $33(61.1)$ & 0.351 & Ns \\
\hline Tiredness, n (\%) & $46(56.8)$ & $36(66.7)$ & 0.283 & Ns \\
\hline Headache, n (\%) & $43(53.1)$ & $34(63.0)$ & 0.289 & Ns \\
\hline Fever, n (\%) & $35(43.2)$ & $32(59.3)$ & 0.080 & Ns \\
\hline Swelling, n (\%) & $28(34.6)$ & $20(37.0)$ & 0.854 & Ns \\
\hline Joint pain, $\mathrm{n}(\%)$ & $24(29.6)$ & $20(37.0)$ & 0.453 & Ns \\
\hline Tingling, n (\%) & $22(27.2)$ & $16(29.6)$ & 0.845 & Ns \\
\hline Itching, n (\%) & $20(24.7)$ & $16(29.6)$ & 0.555 & Ns \\
\hline Chills, n (\%) & $12(14.8)$ & $22(40.7)$ & 0.001 & $* *$ \\
\hline Fainted, n (\%) & $9(11.1)$ & $9(16.7)$ & 0.440 & Ns \\
\hline Breathlessness, n (\%) & $6(7.4)$ & $11(20.4)$ & 0.034 & * \\
\hline Coughing, n (\%) & $8(9.9)$ & $8(14.8)$ & 0.423 & Ns \\
\hline Redness, n (\%) & $6(7.4)$ & $8(14.8)$ & 0.248 & Ns \\
\hline Nausea and vomiting, n (\%) & $7(8.6)$ & $4(7.4)$ & $>0.999$ & Ns \\
\hline Diarrhea, n (\%) & $3(3.7)$ & $4(7.4)$ & 0.437 & Ns \\
\hline Anaphylactic Reaction, n (\%) & $2(2.5)$ & $1(1.9)$ & 0.819 & Ns \\
\hline Swollen Lymph Nodes, n (\%) & $0(0.0)$ & $2(3.7)$ & 0.158 & Ns \\
\hline $\begin{array}{c}\text { Onset of Symptoms (day), } \\
\text { mean }( \pm \text { SD) }\end{array}$ & $1.4( \pm 0.9)$ & $1.5( \pm 0.9)$ & 0.259 & Ns \\
\hline
\end{tabular}

The more "*” in the p-value summary, the greater significance level. While Ns mean non significance; \pm SD: Standard Deviation; BP: Blood Pressure. 


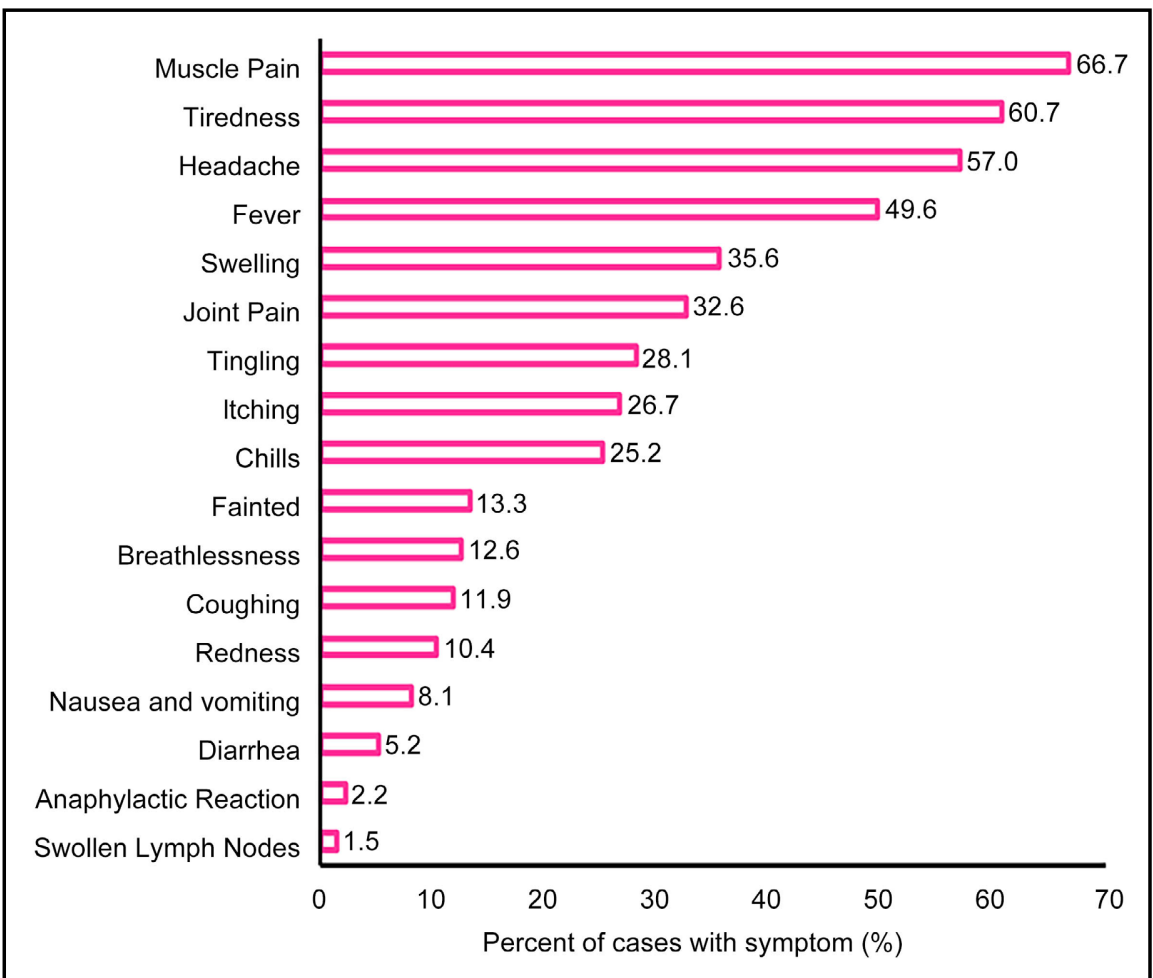

Figure 1. Reported Pfizer-BioNTech COVID-19 vaccine side effects after first and second doses.

\section{Correlation effects between side effects and the participant's gender}

In general, the results showed a significant difference between the number of females (96.5\%) and males (85\%) who suffered from the side effects of the Pfizer-BioNTech COVID-19 Vaccine ( $\mathrm{P}=0.033)$. Male had the highest incidence of muscle pain $(70 \%)$ compared to females $(66.1 \%)(\mathrm{P}=0.8027)$. (62.6 \%) of females reported feeling tired, compared to $(50 \%)$ of males $(\mathrm{P}=0.326)$. For headache, the results showed a significant difference between females and males, Where the percentage of females was $(60.9 \%)$, compared to $(35 \%)$ for males $(\mathrm{P}=$ 0.048). Finally, there were no clear differences in the percentage of fever between females and males, as it was (49.6\%) for females and (50\%) for males ( $\mathrm{P}>0.999)$. Results are presented in (Figure 2).

Spearman Correlation Test was performed on gender and the top four reported side effects (Muscle pain, Tiredness, Headache, and Fever) to find its correlation with each response marker separately. Only statistically significant results are shown.

Gender: Side effects that are strongly associated with females, but not in males, are Headache $(r=-0.185, P=0.031)$, Joint pain $(r=-0.201, P=0.031)$. For males, the significantly associated response markers which were not significant in females are Body mass index $(r=0.232, P=0.006)$, and Anaphylactic reaction $(r=0.220, P=0.010) .95 \%$ confidence interval. Results are presented in Table 2.

Muscle pain: Spearman's correlation coefficient analysis showed that nega- 
tively correlated with: Coughing $(\mathrm{r}=-0.226, \mathrm{P}=0.0081)$, Diarrhea $(\mathrm{r}=-0.189$, $\mathrm{P}=0.0282)$; and positively correlated with: Itching $(\mathrm{r}=0.248, \mathrm{P}=0.003)$, Headache $(r=0.275, P=0.001)$, Tiredness $(r=0.300, P=0.0004)$, Fainted $(r=0.184$, $\mathrm{P}=0.0318)$, Tingling $(\mathrm{r}=0.407, \mathrm{P}>0.0001)$, Onset of Symptoms $(\mathrm{r}=0.183, \mathrm{P}=$ 0.0336), 95\% confidence interval. Results are presented in Table 3.

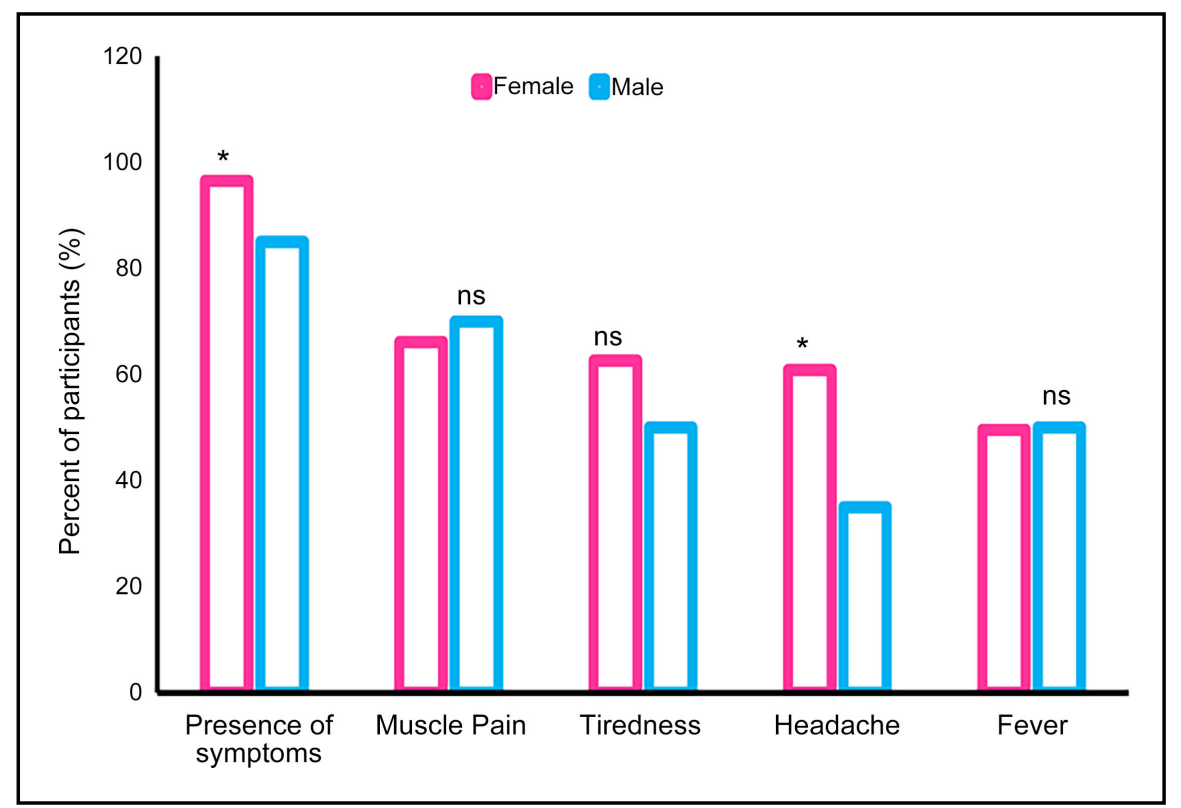

Figure 2. Correlation between side effects and the participant's gender.

Table 2. Impact of a one-unit change in each response marker on gender.

\begin{tabular}{cccc}
\hline Response Marker & r $(95 \%$ confidence interval $)$ & P-value & P-value summary \\
\hline Headache & $-0.185(-0.343$ to -0.017$)$ & 0.0311 & $*$ \\
joint pain & $-0.201(-0.357$ to -0.033$)$ & 0.0194 & $*$ \\
BMI & $0.232(0.066$ to 0.386$)$ & 0.0067 & $* *$ \\
Anaphylactic Reaction & $0.220(0.053$ to 0.375$)$ & 0.0103 & $*$ \\
\hline
\end{tabular}

Table 3. Impact of a one-unit change in each response marker on Muscle pain.

\begin{tabular}{cccc}
\hline Response Marker & $\mathrm{r}(95 \%$ confidence interval) & P-value & P-value summary \\
\hline Itching & $0.248(0.083$ to 0.400$)$ & 0.0036 & $* *$ \\
Headache & $0.275(0.111$ to 0.424$)$ & 0.0012 & $* \star$ \\
Tiredness & $0.300(0.138$ to 0.446$)$ & 0.0004 & $* \star *$ \\
Coughing & $-0.226(-0.381$ to -0.060$)$ & 0.0081 & $* *$ \\
Diarrhea & $-0.189(-0.346$ to -0.020$)$ & 0.0282 & $*$ \\
Fainted & $0.184(0.016$ to 0.343$)$ & 0.0318 & $*$ \\
Tingling & $0.407(0.256$ to 0.539$)$ & $<0.0001$ & $* * * *$ \\
Onset of Symptoms & $0.183(0.014$ to 0.341$)$ & 0.0336 & $*$ \\
\hline
\end{tabular}


Tiredness: Spearman's correlation coefficient analysis showed that negatively correlated with: Body mass index $(r=-0.223, \mathrm{P}=0.0091)$, Diastolic blood pressure $(\mathrm{r}=-0.263, \mathrm{P}=0.0020)$; and positively correlated with: Itching $(\mathrm{r}=0.176, \mathrm{P}$ $=0.0411)$, Fever $(\mathrm{r}=0.403, \mathrm{P}<0.0001)$, Headache $(\mathrm{r}=0.558, \mathrm{P}<0.0001)$, Muscle pain $(r=0.300, P=0.0004)$, Breathlessness $(r=0.213, P=0.0128)$, joint pain $(\mathrm{r}=0.397, \mathrm{P}<0.0001)$, Fainted $(\mathrm{r}=0.270, \mathrm{P}=0.0015)$, Tingling $(\mathrm{r}=0.300, \mathrm{P}=$ $0.0004)$, Chills $(r=0.397, P=0.186), 95 \%$ confidence interval. Results are presented in Table 4.

Headache: Spearman's correlation coefficient analysis showed that negatively correlated with: Age $(r=-0.178, \mathrm{P}=0.0384)$, Gender $(\mathrm{r}=-0.185, \mathrm{P}=0.0311)$; and positively correlated with: Itching $(\mathrm{r}=0.286, \mathrm{P}=0.0008)$, Fever $(\mathrm{r}=0.352, \mathrm{P}$ $<0.0001)$, Muscle pain $(\mathrm{r}=0.275, \mathrm{P}=0.0012)$, Tiredness $(\mathrm{r}=0.558, \mathrm{P}<0.0001)$, Coughing $(r=0.225, P=0.0085)$, Breathlessness $(r=0.194, P=0.0241)$, joint pain $(r=0.411, P<0.0001)$, Fainted $(r=0.252, P=0.0031)$, Tingling $(r=0.243$, $\mathrm{P}=0.0044)$, 95\% confidence interval. Results are presented in Table 5.

Table 4. Impact of a one-unit change in each response marker on Tiredness.

\begin{tabular}{cccc}
\hline Response Marker & $\mathrm{r}($ 95\% confidence interval) & P-value & P-value summary \\
\hline BMI & $-0.223(-0.378$ to -0.056$)$ & 0.0091 & $* *$ \\
Diastolic BP & $-0.263(-0.414$ to -0.099$)$ & 0.0020 & $* *$ \\
Itching & $0.176(0.007$ to 0.335$)$ & 0.0411 & $*$ \\
Fever & $0.403(0.251$ to 0.536$)$ & $<0.0001$ & $* * * *$ \\
Headache & $0.558(0.430$ to 0.664$)$ & $<0.0001$ & $* * * *$ \\
Muscle pain & $0.300(0.138$ to 0.446$)$ & 0.0004 & $* * *$ \\
Breathlessness & $0.213(0.046$ to 0.369$)$ & 0.0128 & $*$ \\
joint pain & $0.397(0.244$ to 0.530$)$ & $<0.0001$ & $* * * *$ \\
Fainted & $0.270(0.106$ to 0.420$)$ & 0.0015 & $* *$ \\
Tingling & $0.300(0.138$ to 0.447$)$ & 0.0004 & $* * *$ \\
Chills & $0.186(0.018$ to 0.345$)$ & 0.0300 & $*$ \\
\hline
\end{tabular}

Table 5. Impact of a one-unit change in each response marker on Headche.

\begin{tabular}{cccc}
\hline Response Marker & r $(95 \%$ confidence interval) & P-value & P-value summary \\
\hline Age & $-0.178(-0.337$ to -0.009$)$ & 0.0384 & $*$ \\
Gender & $-0.185(-0.343$ to -0.017$)$ & 0.0311 & $*$ \\
Itching & $0.286(0.123$ to 0.434$)$ & 0.0008 & $* * *$ \\
Fever & $0.352(0.195$ to 0.492$)$ & $<0.0001$ & $* * * *$ \\
Muscle pain & $0.275(0.111$ to 0.424$)$ & 0.0012 & $* *$ \\
Tiredness & $0.558(0.430$ to 0.664$)$ & $<0.0001$ & $* * * *$ \\
Coughing & $0.225(0.058$ to 0.380$)$ & 0.0085 & $* *$ \\
Breathlessness & $0.194(0.026$ to 0.351$)$ & 0.0241 & $*$ \\
joint pain & $0.411(0.261$ to 0.543$)$ & $<0.0001$ & $* * * *$ \\
Fainted & $0.252(0.087$ to 0.404$)$ & 0.0031 & $* *$ \\
Tingling & $0.243(0.078$ to 0.396$)$ & 0.0044 & $* *$ \\
\hline
\end{tabular}


Fever: Spearman's correlation coefficient analysis showed that positively correlated with: Headache $(\mathrm{r}=0.352, \mathrm{P}<0.0001)$, Tiredness $(\mathrm{r}=0.403, \mathrm{P}<0.0001)$, joint pain $(r=0.226, P=0.0083)$, Chills $(r=0.243, P=0.0045), 95 \%$ confidence interval. Results are presented in Table 6.

\section{Discussion}

Since starting the global health crisis of COVID-19 pandemic in January 2020, precautionary measures have been taken by most countries to control SARS-CoV-2 transmission anticipating the rapid production of safe and effective vaccines [14]. After developing a number of vaccines endorsed by the Centers for Disease Control and Prevention (CDC) and WHO to be introduced to public worldwide, the Libyan national regulatory authority has approved four vaccines (AstraZeneca, Pfizer, Moderna, Sinovac, Sputnik V and Janssen (Johnson \& Johnson's) to be used in Libya to combat the spread of SARS-CoV-2, Pfizer vaccine first arrived in April-2021 restrictedly for health care workers and elderly people. Since the end of July, the vaccination campaigns have been strengthened with the opening of new vaccination centers across Libya and facilitating free access to all Libyans for vaccination [15] [16] [17] [18].

Thus this study aimed to report and follow up on potential short term side effects of Pfizer vaccine for healthy young people from July to September 2021 at the Faculty of Pharmacy, Omar Al-Mukhtar University, Al-Bayda, Libya.

The side effects of the Pfizer-BioNTech COVID-19 Vaccine reported in this study showed an increase in the number of participants who were suffering from side effects after receiving the second dose with $(53,98.1 \%)$, compared to those who reported side effects after receiving the first dose $(75,92.6 \%)$. When comparing the second dose and the first dose of the vaccine, a report published by by the U.S FDA revealed that the frequency of local side effects was slightly higher after the second dose compared to the first dose [19]. Such a result was showed by Abu-Hammad et al:; 2021 and Lim, S.M et al.; 2021 where the adverse events were more common after second dose [20] [21].

According to the study conducted by Elnaem, M.H.; et al. 2021, about $40 \%$ of the side effects occurred more with the second dose, particularly those who received the Pfizer-BioNTech vaccine compared to those who received the Sinovac or AstraZeneca vaccine [22]. Riad, A.; 2021 reported that the people with two doses were generally associated with a higher frequency of side effects includes, the prevalence of injection site pain, swelling, redness, fatigue, headache, nausea, muscle pain, lymphadenopathy [9].

Table 6. Impact of a one-unit change in each response marker on Fever.

\begin{tabular}{cccc}
\hline Response Marker & r $(95 \%$ confidence interval) & P-value & P-value summary \\
\hline Headache & $0.352(0.195$ to 0.492$)$ & $<0.0001$ & $* * * *$ \\
Tiredness & $0.403(0.251$ to 0.536$)$ & $<0.0001$ & $* * * *$ \\
joint pain & $0.226(0.059$ to 0.380$)$ & 0.0083 & $* *$ \\
Chills & $0.243(0.077$ to 0.395$)$ & 0.0045 & $* *$ \\
\hline
\end{tabular}


Notably, the most frequently reported adverse reactions in the current study were (Muscle pain (66.7\%), Tiredness (60.7\%), Headache (57.0\%), and Fever (49.6\%) these were common and consistent with other studies as Ahlam Alghamdi et al.; 2021 stated that tiredness, headache, and fever were observed to be the most common side effects of the vaccine [23]. In another study Riad, A.; 2021, reported that injection site pain (89.8\%), fatigue $(62.2 \%)$, headache $(45.6 \%)$, muscle pain $(37.1 \%)$, and chills (33.9\%) were the most commonly reported side effect [9].

In a research study conducted in Italy by Giuseppe Lippi.; 2021, fever was the most frequent mild side effect after administration of Pfizer vaccines (13.2\%), followed by headache $(10.3 \%)$, myalgia $(8.7 \%)$, pain at injection site $(8.3 \%)$, arthralgia (7.9\%), and tiredness [7]. Giuseppe Lippi also stated that, the frequency of pain at injection site, tiredness/fatigue, lymphadenopathy, and malaise was higher after Pfizer Comirnaty than with AstraZeneca and Moderna vaccination. One more study by Elnaem, M.H.; et al. 2021, has highlighted that pain at the injection site $(61.1 \%)$ and tiredness $(48.8 \%)$ were commonly reported side effects in participants who received Pfizer vaccine [22].

A focus on the gender-related differences concerning adverse reactions involved in the present study, which showed that, the occurrence of the side effects in females (96.5\%) were more likely than males (85\%) and were similar to those reported by previous studies that have shown that, men were less likely to suffer adverse side effects than women [9] [22]. Differences in vaccination response between males and females have been previously reported, where biological differences such as endocrine and sex hormones in each gender play an important role in experiencing the bacterial and viral vaccine high response in females [24]. According the spearman correlation used in the present study, headache and joint pain increase with females rather than males. Other markers used appear at the same level of severity including fever, headache, tiredness and muscle pain. Results are presented in Figure 2.

Onset of symptoms in this study were quit similar after both doses, in first dose (baseline) were started to appear less than 24 hrs 6 (7.4\%), 24 to 72 hrs 57 $(70.4 \%)$ and on the third day or later 18 (22.2\%). While the symptoms after the second dose (final) were started to appear less than $24 \mathrm{hrs} 1$ (1.85\%), 24 to $72 \mathrm{hrs}$ $38(70.3 \%)$ and on the third day or later $15(27.7 \%)$. The result of another study was completely different in terms of the time of appearance of side effects, especially between the first and second day, and the time of their appearance was as follow: First day 257 (84\%), Second day 47 (15\%) and on the third day or later 3 (1\%) [25].

\section{Conclusion}

The most common reported side effects after both doses of the Pfizer-BioNTech COVID-19 vaccine among pharmacy students were Muscle pain, Tiredness, headache, and fever. These reported short-term side effects of vaccines were 
highly consistent with the data published in Pfizer fact sheet in terms of their association with the younger age group and the second dose. Although the several side effects were reported throughout the present study, it is noticed that the reported side effects were common but not serious, and participants were able to attend their university classes and carry out their daily activities, so we recommend taking the vaccine, especially for young people.

\section{Authors Contributions}

Taher I. Shailabi: Methodology, Conceptualization, Survey preparation, data collection, Funding acquisition, and Writing-original draft \& editing. Nagat $\mathrm{H}$. Bubtina: Validation, Writing - review \& editing, Supervision, and Investigation. Elham O. Borwis, Naeima Betamar and Nisreen Saed Majeed: Writing-review \& editing. Guma Abdeldaim: Review \& Editing, Supervision.

\section{Acknowledgements}

We have to express our appreciation to the students of the Faculty of Pharmacy, Omar Al-Mukhtar University, Al-Bayda, Libya, for their voluntary participation in this study.

\section{Conflicts of Interest}

The authors declare no conflicts of interest regarding the publication of this paper.

\section{References}

[1] El-Shitany, N.A., Harakeh, S., Badr-Eldin, S.M., Bagher, A.M., Eid, B., Almukadi, H., Alghamdi, B.S., Alahmadi, A.A., Hassan, N.A., Sindi, N., Alghamdi, S.A., Almohaimeed, H.M., Mohammedsaleh, Z.M., Al-Shaikh, T.M., Almuhayawi, M.S., Ali, S.S. and El-Hamamsy, M. (2021) Minor to Moderate Side Effects of Pfizer-BioNTech COVID-19 Vaccine among Saudi Residents: A Retrospective CrossSectional Study. International Journal of General Medicine, 14, 1389-1401. https://doi.org/10.2147/IJGM.S310497

[2] Cucinotta, D. and Vanelli, M. (2020) WHO Declares COVID-19 a Pandemic. Acta Bio-Medica: Atenei Parmensis, 91, 157-160.

[3] Polack, F.P., Thomas, S.J., Kitchin, N., Absalon, J., Gurtman, A., Lockhart, S., Perez, J.L., Pérez Marc, G., Moreira, E.D., Zerbini, C., Bailey, R., Swanson, K.A., Roychoudhury, S., Koury, K., Li, P., Kalina, W.V., Cooper, D., Frenck, R.W., Hammitt, L.L., Türeci, Ö. and C4591001 Clinical Trial Group (2020) Safety and Efficacy of the BNT162b2 mRNA Covid-19 Vaccine. The New England Journal of Medicine, 383, 2603-2615. https://doi.org/10.1056/NEJMoa2034577

[4] World Health Organisation (2020) Draft Landscape and Tracker of COVID-19 Candidate Vaccines. World Health Organisation (WHO), Geneva. https://www.who.int/publications/m/item/draft-landscape-of-covid-19-candidate-v accines

[5] Mascellino, M.T., Di Timoteo, F., De Angelis, M. and Oliva, A. (2021) Overview of the Main Anti-SARS-CoV-2 Vaccines: Mechanism of Action, Efficacy and Safety. Infection and Drug Resistance, 14, 3459-3476. https://doi.org/10.2147/IDR.S315727 
[6] Kashte, S., Gulbake, A., El-Amin III, S.F., et al. (2021) COVID-19 Vaccines: Rapid Development, Implications, Challenges and Future Prospects. Human Cell, 34, 711-733. https://doi.org/10.1007/s13577-021-00512-4

[7] Lippi, G., Mattiuzzi, C. and Henry, B. (2021) Mild Adverse Reactions after COVID-19 Vaccination: Updated Analysis of Italian Medicines Agency Data. https://doi.org/10.2139/ssrn.3817988

[8] Menni, C., Klaser, K., May, A., Polidori, L., Capdevila, J., Louca, P., Sudre, C.H., Nguyen, L.H., Drew, D.A., Merino, J., Hu, C., Selvachandran, S., Antonelli, M., Murray, B., Canas, L.S., Molteni, E., Graham, M.S., Modat, M., Joshi, A.D., Spector, T.D., et al. (2021) Vaccine Side-Effects and SARS-CoV-2 Infection after Vaccination in Users of the COVID Symptom Study App in the UK: A Prospective Observational Study. The Lancet Infectious Diseases, 21, 939-949. https://doi.org/10.1016/S1473-3099(21)00224-3

[9] Riad, A., Pokorná, A., Attia, S., Klugarová, J., Košč́́k, M. and Klugar, M. (2021) Prevalence of COVID-19 Vaccine Side Effects among Healthcare Workers in the Czech Republic. Journal of Clinical Medicine, 10, 1428. https://doi.org/10.3390/jcm10071428

[10] Riad, A., Schünemann, H., Attia, S., Peričić, T.P., Žuljević, M.F., Jürisson, M., Kalda, R., Lang, K., Morankar, S., Yesuf, E.A., Mekhemar, M., Danso-Appiah, A., Sofi-Mahmudi, A., Pérez-Gaxiola, G., Dziedzic, A., Apóstolo, J., Cardoso, D., Marc, J., Moreno-Casbas, M., Wiysonge, C.S., Qaseem, A., Gryschek, A., Tadić, I., Hussain, S., Khan, M.A., Klugarova, J., Pokorna, A., Koščík, M. and Klugar, M. (2021) COVID-19 Vaccines Safety Tracking (CoVaST): Protocol of a Multi-Center Prospective Cohort Study for Active Surveillance of COVID-19 Vaccines' Side Effects. International Journal of Environmental Research and Public Health, 18, 7859. https://doi.org/10.3390/ijerph18157859

[11] Gargano, J.W., Wallace, M., Hadler, S.C., Langley, G., Su, J.R., Oster, M.E., et al. (2021) Use of mRNA COVID-19 Vaccine after Reports of Myocarditis among Vaccine Recipients: Update from the Advisory Committee on Immunization Practices-United States, June 2021. Morbidity and Mortality Weekly Report, 70, 977-982. https://doi.org/10.15585/mmwr.mm7027e2

[12] Centers for Disease Control and Prevention (2021) What to Expect at Your Appointment to Get Vaccinated for COVID-19. CDC. Vaccines.

https://www.cdc.gov/coronavirus/2019-ncov/vaccines/expect.html

[13] Van Delden, J.J. and van der Graaf, R. (2017) Revised CIOMS International Ethical Guidelines for Health-Related Research Involving Humans. JAMA, 317, 135-136. https://doi.org/10.1001/jama.2016.18977

[14] Algaissi, A.A., Alharbi, N.K., Hassanain, M. and Hashem, A.M. (2020) Preparedness and Response to COVID-19 in Saudi Arabia: Building on MERS Experience. Journal of Infection and Public Health, 13, 834-838. https://doi.org/10.1016/j.jiph.2020.04.016

[15] World Health Organization (WHO) Office in Libya Report, Health Response to COVID-19 WHO Update \#25. Reporting Period: 1-31 March 2021.

[16] World Health Organization (WHO) Office in Libya Report, Health Response to COVID-19 WHO Update \#28. Reporting Period: 1-31 June 2021.

[17] World Health Organization (WHO) Office in Libya Report, Health Response to COVID-19 WHO Update \#30. Reporting Period: 1-31 August 2021.

[18] United Nations Office for Coordination of Humanitarian Affairs (OCHA) LIBYA COVID-19 Vaccination Rates on the Rise. 
https://reports.unocha.org/en/country/libya/card/2LCjAJmnvL

[19] Centres for Diseases Control and Prevention (CDC) Reactions and Adverse Events of the Pfizer-BioNTech COVID-19 Vaccine.

https://www.cdc.gov/vaccines/covid-19/info-by-product/pfizer/reactogenicity.html

[20] Abu-Hammad, O., Alduraidi, H., Abu-Hammad, S., Alnazzawi, A., Babkair, H., Abu-Hammad, A., Nourwali, I., et al. (2021) Side Effects Reported by Jordanian Healthcare Workers Who Received COVID-19 Vaccines. Vaccines, 9, 577. https://doi.org/10.3390/vaccines9060577

[21] Lim, S.M., Chan, H.C., Santosa, A., Quek, S.C., Liu, E.H.C. and Somani, J. (2021) Safety and Side Effect Profile of Pfizer-BioNTech COVID-19 Vaccination among Healthcare Workers: A Tertiary Hospital Experience in Singapore. Annals-Academy of Medicine Singapore, 50, 703-711.

https://doi.org/10.47102/annals-acadmedsg.2021160

[22] Elnaem, M.H., Mohd Taufek, N.H., Ab Rahman, N.S., Mohd Nazar, N.I., Zin, C.S., Nuffer, W. and Turner, C.J. (2021) COVID-19 Vaccination Attitudes, Perceptions, and Side Effect Experiences in Malaysia: Do Age, Gender, and Vaccine Type Matter? Vaccines, 9, 1156. https://doi.org/10.3390/vaccines9101156

[23] Alghamdi, A., Ibrahim, A., Almutairi, R., Joseph, M., Alghamdi, G. and Alhamza, A. (2021) A Cross-Sectional Survey of Side Effects after COVID-19 Vaccination in Saudi Arabia: Male versus Female Outcomes. Journal of Advanced Pharmacy Education and Research, 11, 51-56. https://doi.org/10.51847/bCwca2qGfP

[24] Klein, S.L. and Flanagan, K.L. (2016) Sex Differences in Immune Responses. Nature Reviews Immunology, 16, 626-638. https://doi.org/10.1038/nri.2016.90

[25] Alhazmi, A., Alamer, E., Daws, D., Hakami, M., Darraj, M., Abdelwahab, S., Maghfuri, A., et al. (2021) Evaluation of Side Effects Associated with COVID-19 Vaccines in Saudi Arabia. Vaccines, 9, 674. https://doi.org/10.3390/vaccines9060674

\section{Abbreviations and Acronyms}

CDC, Centers for Disease Control and Prevention; SARS-CoV-2, Coronavirus 2; CIOMS, Council for International Organizations of Medical Sciences; FDA, Food and Drug Administration; WHO, World Health Organization; SREC, Scientific Research Ethics Committee. 